\title{
Contents of Journals Relating to Back and Musculoskeletal Rehabilitation
}

\section{NeuroRehabilitation, Vol. 6, No. 1, January 1996}

Introduction

N.D. Zasler

Nomenclature: evolving trends

N.D. Zasler (USA)

Medical management of the comatose, vegetative, or minimally responsive patient

M.E. Sandel (USA)

Predicting outcome in the slow to respond traumatically brain-injured patient: Acute and subacute parameters

R.D. Zafonte, F.M. Hammond, J. Peterson (USA)

Rehabilitation nursing management of persons in low level neurologic states

T. Antoinette (USA)

Standardized assessment instruments for minimally-responsive, brain-injured patients

M.W. O'Dell, P. Jasin, N. Lyons, M. Stivers, F. Meszaros (USA)

Pharmacology of attention and arousal in the low level patient

E. Elovic (USA)

Sensory stimulation: theoretical perspectives and the evidence for effectiveness

J.T. Giacino (USA)

Recent advances in the development of practice parameters: The vegetative state

J. Rosenberg, S. Ashwal (USA)

New books in print

\section{NeuroRehabilitation, Vol. 6, No. 2, April 1996}

Introduction

J.D. Banja (USA)

Interdisciplinary team member perceptions of ethical issues in traumatic brain injury rehabilitation

V.M. Tarvydas, L. Shaw (USA)

Ethical issues in the evaluation of competence in persons with acquired brain injuries

M. Rosenthal, I. Lourie (USA)

Assessing client competence to participate in rehabilitation decision making

V.S. Auerbach, J.D. Banja (USA)

The role of an ethics committee in a rehabilitation setting

R.T. Guenther, L.J. Weber (USA)

The Americans with Disabilities Act: An ethical perspective as the law develops

W. Wilkinson, C. Dresden (USA) 